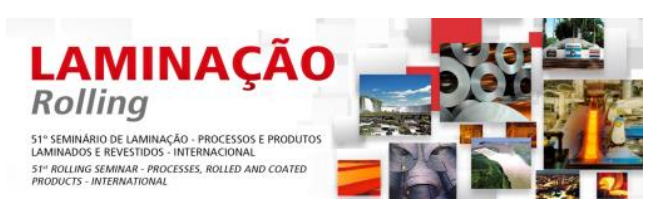

\title{
CHINA ENTERS THE HIGH-QUALITY, ULTRA-THIN STRIP MARKET ARVEDI ESP INSTALLATIONS IN CHINA*
}

Andreas Jungbauer ${ }^{1}$ Sergey Bragin ${ }^{1}$ Robert Linsbod ${ }^{1}$

\begin{abstract}
Two Arvedi ESP plants going into operation in 2015 will allow a Chinese steel producer to better serve the extremely attractive local and export markets for highquality, thin-gauge strip products. The energy consumption and the related costs are reduced by up to $45 \%$ compared to conventional casting and rolling processes. This also means a major reduction in $\mathrm{CO} 2$ emissions. The new plants are designed for an annual production capacity of $2 \times 2.55$ million tons of high-quality, ultra-thin, hotrolled strip products with widths of up to $1,600 \mathrm{~mm}$ and thicknesses down to $0.8 \mathrm{~mm}$. The project scope also features a comprehensive training and assistance package for plant start-up and operations by personnel from the existing ESP plant at Acciaieria Arvedi SpA, Italy. The plant setup, the trainings and assistance program as well as latest results from the ESP plant in Italy will be presented. While this project is under execution three further ESP lines have been ordered by the same customer summing up now to five ESP lines at the same location.

Keywords: Ultra-thin hot strip; Hot-rolled strip $0.8 \mathrm{~mm}$; Endless rolling; High capacity TSDR.
\end{abstract}

Siemens VAl Metals Technologies GmbH, Linz, Austria.

* Technical contribution to the 51st Rolling Seminar - Processes, Rolled and Coated Products, October $28^{\text {th }}$ to $31^{\text {st }}$, 2014, Foz do Iguaçu, PR, Brazil. 


\section{INTRODUCTION}

In 2013 a Chinese steel producer placed an order with Siemens Metals Technologies for the supply of the first two Arvedi ESP (Endless Strip Production) lines. These castingrolling facilities will be part of a new steelmaking facility currently under construction in Eastern China. With a production of 708 million tons of steel in 2012 China is the world's biggest steel producer contributing almost $50 \%$ to world steel production. Nevertheless Chinese steel producers are facing a more demanding market environment. The Chinese steel market is more and more saturated with commodity steels and profit can be made only with quality steels and by pushing cost efficiency. Approvals for capacity increasing investments are getting more difficult - only new technologies and green technologies have a chance to be approved. The customer is focussing with the investment in ESP technology on the attractive market of ultra-thin gauges in China and also the export market is in focus. The new plants are designed for an annual production capacity of $2 \times 2.55$ million tons of high-quality, ultra-thin, hot-rolled strip products with widths of up to $1,600 \mathrm{~mm}$ and thicknesses down to $0.8 \mathrm{~mm}$. Mild steels, carbon steels, high-strength low alloyed (HSLA) grades and dual-phase steels will be produced. The energy consumption and the related costs are reduced by up to $45 \%$ compared to conventional casting and rolling processes. This also means a major reduction in $\mathrm{CO} 2$ emissions.

Siemens is responsible for the engineering of the Arvedi ESP plants and will supply mechanical equipment, media-control systems, technological packages and automation systems. The entire line is controlled by completely integrated basic (Level 1) and process optimization (Level 2) automation, which fully regulate all casting and rolling operations.

The project scope also features a comprehensive training and assistance package. This will be comprised of theoretical and practical training for the customer's operational personnel on the existing ESP plant of Acciaieria Arvedi SpA in Cremona, Italy, in addition to start-up and operational support by specialists from Acciaieria Arvedi.

During the construction phase of the first two plants the same customer ordered three further ESP lines to be located at the same location. With the now totally five ESP lines a good basis is given to guide the high quality thin strip market in China.

\section{PLANT SETUP}

In the Arvedi ESP process hot-rolled coils are produced in a linked casting and rolling plant directly from liquid steel in a continuous and uninterrupted manufacturing process. The line commences with the casting of a thin strand that is subsequently rolled to an intermediate thickness of $10-20 \mathrm{~mm}$ in a 3-stand high-reduction mill positioned at the end of the caster. After reheating in an induction heater, rolling of the transfer bar to the targeted end thickness is performed in a 5-stand finishing mill followed by laminar strip cooling. Strip cutting is then carried out by means of a high-speed shear immediately prior to coiling to coil weights of up to 32 tons. The process automation comprises motor and drive solutions as well as process models which control the machine from the mold to the downcoiler. A modern integrated human machine interface provides a complete overview for the operator.

\footnotetext{
* Technical contribution to the 51st Rolling Seminar - Processes, Rolled and Coated Products, October $28^{\text {th }}$ to $31^{\text {st }}$, 2014, Foz do Iguaçu, PR, Brazil.
} 


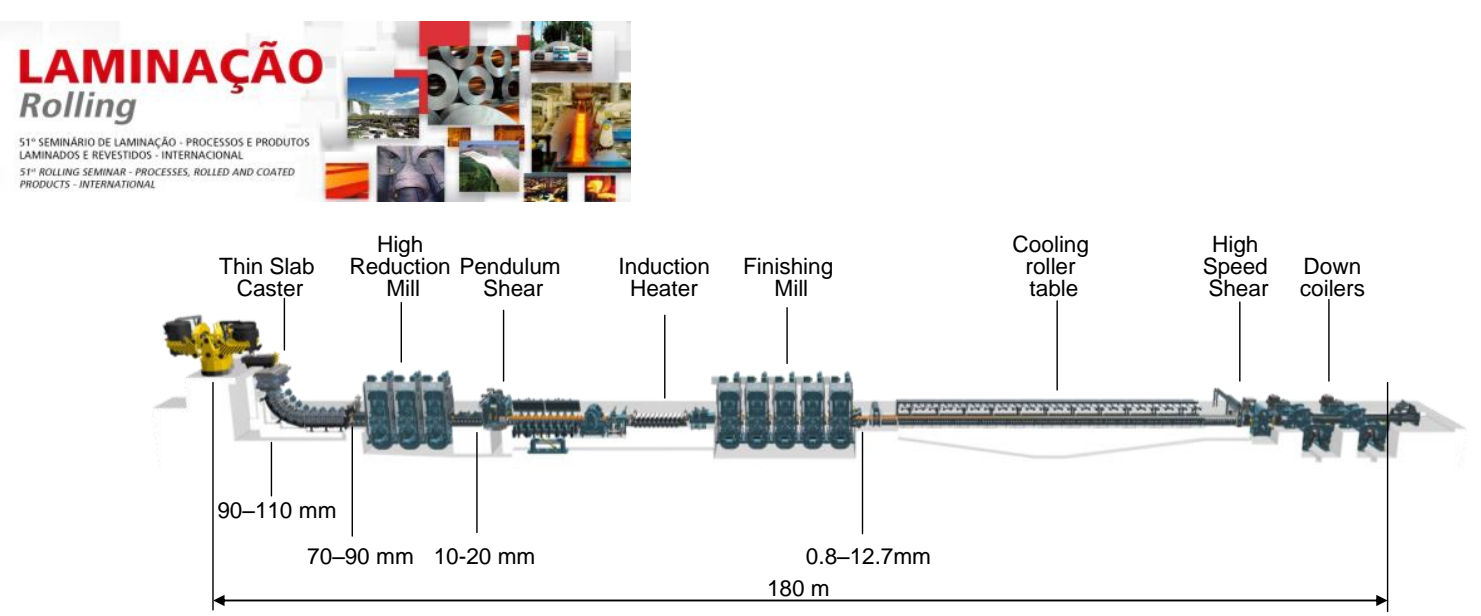

Figure 1: Plant Overview

The new plants in China will be in design very close to the existing plant in Cremona, Italy. Liquid steel is supplied by a 300 ton ladle. The bow type caster with continuous bending and unbending is equipped with a straight mold of thicknesses from 90-110 mm featuring online width adjustments. Online width adjustments over the full mold width range are supported by the proven DynaWidth adjustment technology. This allows an accurate setting of the target width without the necessity of an aedger. The machine will be equipped with 11 segments supporting a metallurgical length of $20.2 \mathrm{~m}$. The three, high reduction mill stands are placed right after the last caster segment such using the internal energy of casting for the first rolling step and allowing perfect crown and wedge control as the hot core of the cast strand is softer and serves better formability for shape control. The pendulum shear allows the cutting of full thickness and is used for cutting and disconnecting the dummy bar. Further cuts for batch operation are done only for some coils at sequence start and sequence end. The major part of coils - more than $90 \%$ - are produced in endless mode and cut by the high speed shear at the end of the machine. After the pusher piler section which serves for dummy bar handling, start and end operations and for downstream activities follows the induction heater. With its short length of only $10 \mathrm{~m}$ it contributes to extremely low scale building as the intermediate strip passes here in less than 15 seconds. There is only one descaler required in the line which is placed right in front of the five - stand finishing mill. As shaping of the strip is already performed in the high reduction mill, the last stands of the finishing mill can be equipped with conventional work roll contours allowing long stroke shifting. Together with the avoided shocks that occur in batch operated plants during head threading this permits extremely long work roll life time which will be discussed later. The total rolling power of $43.5 \mathrm{MW}(2 \times 3+5.5 \mathrm{MW}$ at HRM and $3 \times 7+2 \times 5.5 \mathrm{MW}$ at FM) seems very low compared to known casting and rolling processes. It can be explained by the fact that due to the intermediate heating the strip is always in the optimum temperature window for rolling which serves not only for best product properties due to best activation of recrystallization but also lowers the energy consumption. As operating mainly in endless mode the work roll lubrication and the laminar cooling can stay switched on continuously supporting constant strip quality from head to tail. The coil cutting in endless mode happens tension free just in front of the down coilers. The coils with a weight of up to 32 tons show uniform properties from head to tail. The tracking system of the fully integrated automation system ensures exact cuts supporting coil scheduling to allow product qualities according all selling standards even during changes in steel grade, width as well as flying gauge changes. The process as well as the complete machine and automation is covered by several patents from Arvedi and

* Technical contribution to the 51st Rolling Seminar - Processes, Rolled and Coated Products, October $28^{\text {th }}$ to $31^{\text {st }}$, 2014, Foz do Iguaçu, PR, Brazil. 


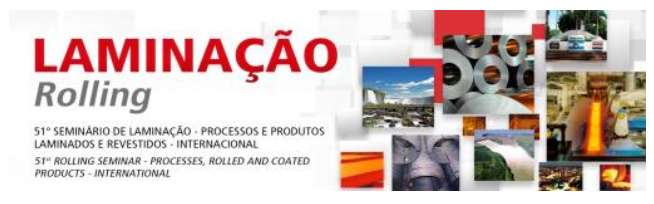

Siemens. Starting with the process patent EP 1558408 there are patents for the mold and SEN shape, Flying gauge change in rolling mill, automatic drive load adjustment in rolling mill train and further.

Looking on the overall Layout, the 180-m-long plants are far more compact than conventional casting and rolling mills. The two lines are positioned in mirrored arrangement, placing the drives outside of the two lines and operation as well as roll shop in between. With short plant length not only the investment in land is minimized. Also the Turn-key driving cost parameter like foundations, bays, piping and cabling as well as erection are reduced drastically.

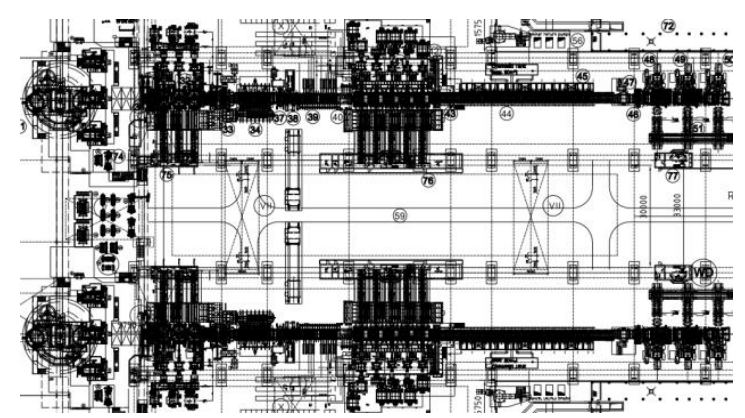

Figure 2: Layout of the ESP plant in China

\subsection{Product Mix}

The product mix of the new plants will be well distributed between ultra low / low carbon, medium carbon steels and contain also High Strength Low Alloyed (HSLA) steels and Dual phase. Even capable for higher gauges of $12.7 \mathrm{~mm}$ the ESP lines will concentrate on thin gauges and the operating range is defined from $0.8-6 \mathrm{~mm}$.

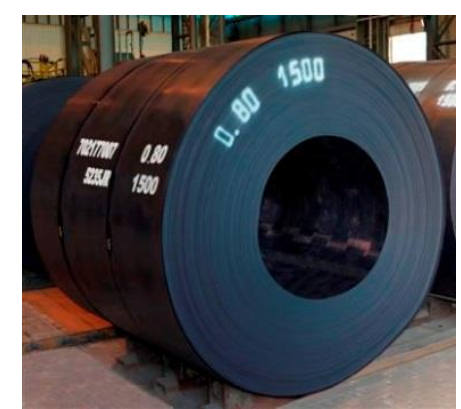

Figure 3: $0.8 \mathrm{~mm}$ Coil at Arvedi ESP plant in Cremona

2-step rolling in endless operation in not only featuring best performance at ultra thin gauges but also allowing the highest width to thickness ratio which results in higher average strip widths compared to conventional casting and rolling. On the one hand this is the best possibility to diversify on the saturated and tough Chinese steel market. On the other hand the combination with the existing hot strip mill gives special synergies. The hot strip mill will be free to optimize the production scheme, which will result in higher overall productivity with no or minor additional investments.

\footnotetext{
* Technical contribution to the 51st Rolling Seminar - Processes, Rolled and Coated Products, October $28^{\text {th }}$ to $31^{\text {st }}$, 2014, Foz do Iguaçu, PR, Brazil.
} 


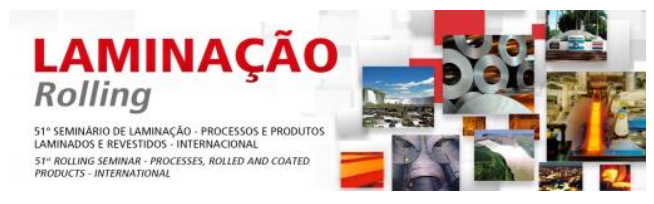

\subsection{Extended Training and Technical Assistance}

Quick Ramp-up and reaching of stable high output is essential for plant operators for quick return on investment. Training and technical assistance is a topic which is usually under estimated in the steel branch. On the other hand it is getting more and more difficult to find an experienced steel producer who is open enough to allow other companies a deep insight view in his plant and a know how transfer. Exactly this topic was essential for the contract of the new installations in China. Arvedi, licensor of Arvedi ESP technology, offers not only a basic training at his plant in Cremona, Italy. Optionally a certain group of operators will stay 2 months longer in Cremona - fully involved in the daily production process. Equipped with this experience the Chinese operators will come back to their home plant with the highly productive spirit of Arvedi Steel and play a highly motivated leading role at the new plant.

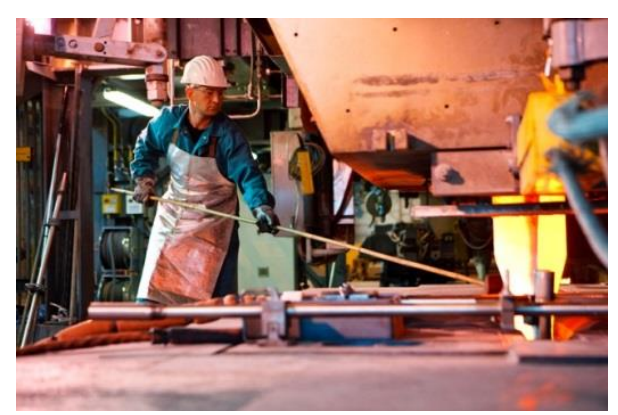

Figure 4: Caster Operator at Arvedi ESP plant in Cremona

To ensure not only having most modern equipment but also full productivity at highest level of excellence the Chinese steel producer has also ordered a technical assistance package from Arvedi. Six Arvedi Experts will go to China for the first year of operation, ensuring optimum ramp-up know how. The combination of experienced Arvedi experts with well-trained customer's personnel shall result in high quality final products right from the beginning and establish a highly productive working climate at the new facility.

\subsubsection{The training program}

The Basic training incorporates the theoretical training from Siemens VAl in Linz and Erlangen covering content for the mechanical, electric and automation equipment followed by a three weeks theoretical and practical training at the ESP line in Cremona. Optionally the Module 2 with extended practical training can be included in the contract. After the training during cold commissioning the optional Module 3 contains finally the technical assistance of Arvedi experts. Essential for a successful training is that the trainees remain unchanged and take part in the full sequence.

\footnotetext{
* Technical contribution to the 51st Rolling Seminar - Processes, Rolled and Coated Products, October $28^{\text {th }}$ to $31^{\text {st }}$, 2014, Foz do Iguaçu, PR, Brazil.
} 


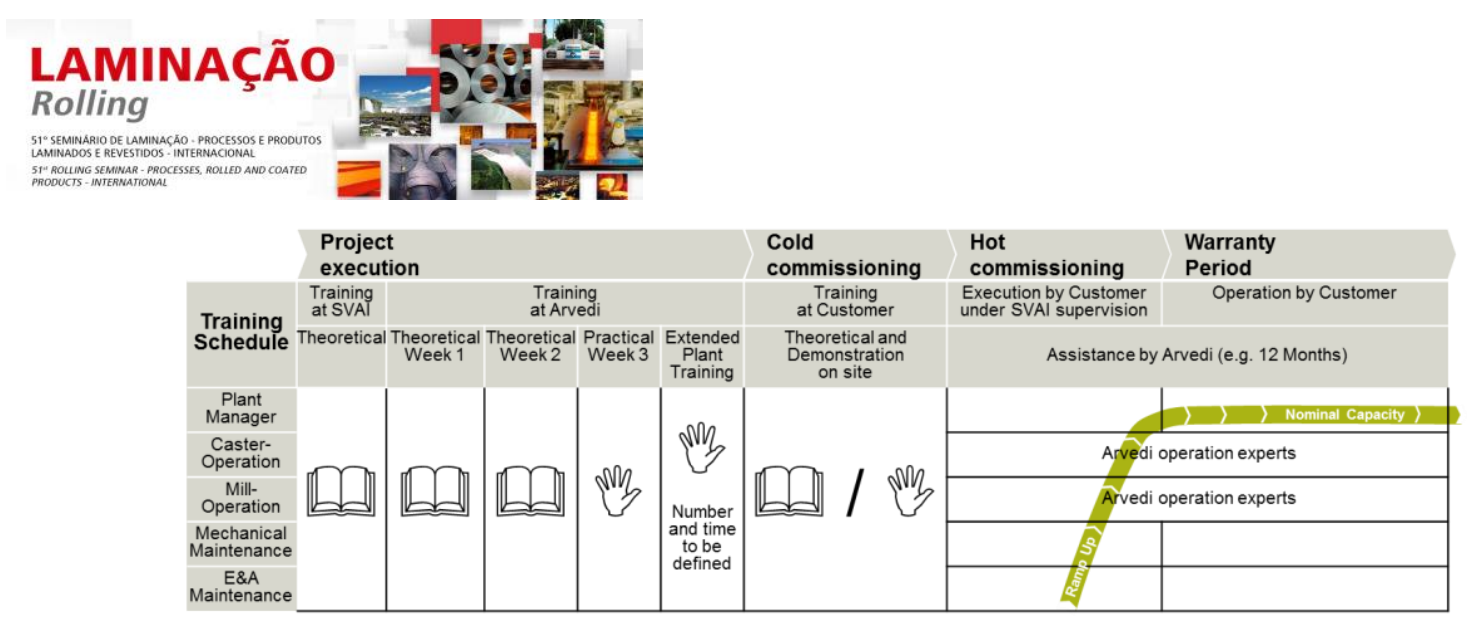

Figure 5: Extended Training and Technical assistance with Arved

\section{RESULTS AT THE ARVEDI ESP LINE IN CREMONA AS BASIS FOR THE NEW PLANTS IN CHINA}

The two ESP plants in China will base directly on the ESP line in Cremona. As the original concept for the master plant in Cremona worked as calculated and designed right from the beginning the concept and design can be kept also for further installations like the new lines in China. The layout and the expected results of the new plants are based on the performance of the existing ESP production line at Acciaieria Arvedi. This plant has been successfully operating since 2009. Thanks to the unique mold design and the installed technological packages, highly stable casting conditions are achieved that reduce breakout rates to only $0.07 \%$. As a result of the endless strip-production mode of Arvedi ESP lines, repeated threading into the individual rolling stands is not necessary. This is the basis for the production of ultra-thin strip gauges down to $0.8 \mathrm{~mm}$ thicknesses. The tolerance values for the required strip geometry are fully met along the entire length of the rolled product. Endless production is also decisive for assuring the homogeneity of the steel microstructure, grain size, yield strength and tensile strength. Because the strip is continually under tension, the cobble rate is below $0.1 \%$. Yield values exceeding $98 \%$ are reached because cropping of the strip head and tail ends is not necessary.

Several technological milestones were achieved, including the casting of $80 \mathrm{~mm}$ thin strands at speeds in excess of six meters per minute and hot-strip rolling down to a thickness of $0.8 \mathrm{~mm}$. Strip dimensions meet the geometrical requirements for cold rolling, allowing the conventional cold-rolling process step to be dispensed with for many applications.

\subsection{Breakout Rate}

With regard to Breakouts the ESP caster in Cremona definitely writes world record history. The past years showed on average only 5 breakouts per year resulting in $0,07 \%$ breakout rate. This is not only essential for the stable production but is also an enormous cost advantage compared to the usually much higher breakout rates of other thin slab casters which reach values up to 4 breakouts per month. Taking into account that a breakout costs including the production losses more than 100,000 Euro this gives an annual advantage of some million Euros. The excellent performance is based on the one hand on the patented shape of the funnel mold and Submerged entry nozzle as well as the fact that the caster with continuous bending and unbending builds much lower

* Technical contribution to the 51st Rolling Seminar - Processes, Rolled and Coated Products, October $28^{\text {th }}$ to $31^{\text {st }}$, 2014, Foz do Iguaçu, PR, Brazil. 


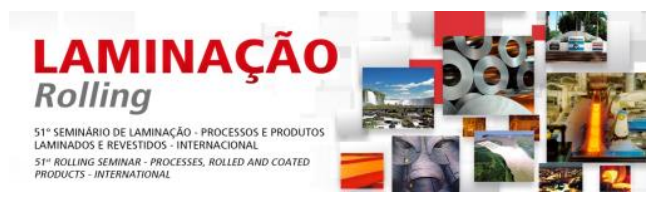

than vertical-solid bending machines thus reducing the ferrostatic pressure and bulging behavior.

\subsection{Work Roll Lifetime}

Usual sequence length on the Arvedi ESP plant in Cremona is about eight hours with up to eleven ladles resulting in almost 3000 tons high quality strip. As shown in figure 6 the thickness is changed online by flying gauge change starting from thicker strips, going to thinnest gauges. ESP allows now on hot rolling what is state of the art for cold rollers since years. After remaining for hours on minimum gauge, at the end of the sequence the thickness is increased again. Intelligent scheduling allows off-gauge free production. The strip is cut on half way of gauge change and both strips are fully within standard. Such minimizing the off material to just some start and end scrap as well as minimized scale due to the usage of the only $10 \mathrm{~m}$ long induction heater yield of more than $98 \%$ from liquid steel to good coil is reached as yearly average. Due to the flying gauge change in endless operation the work rolls are not exposed to the regular shock as known from batch rolling. Paired with the long stroke shifting capability and wear compensation model on the last finishing stands this permits extremely long work roll life time as shown in figure 6 where the more than 4 hours period of $1 \mathrm{~mm}$ strip lead to 170 rolled kilometers on the work rolls of last finishing stand.

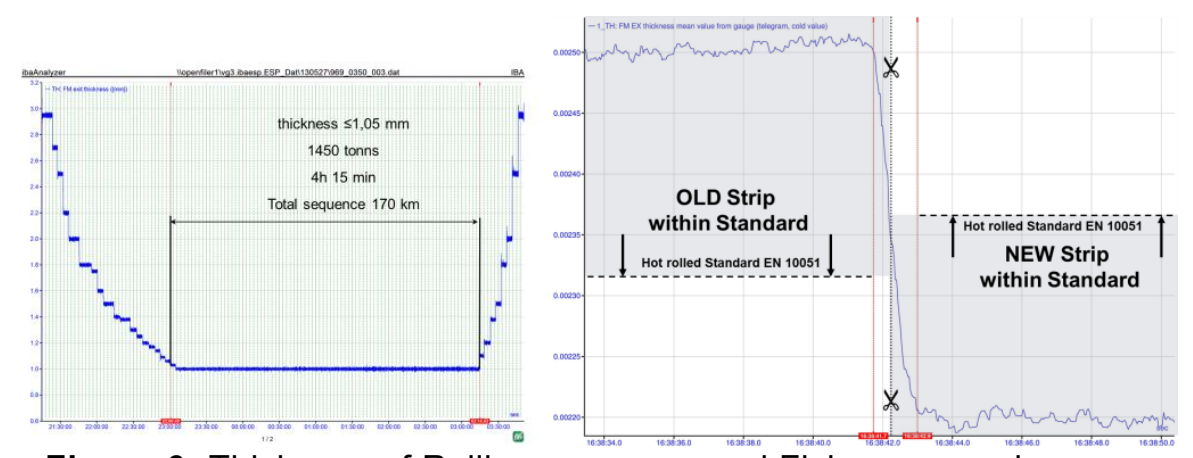

Figure 6: Thickness of Rolling sequence and Flying gauge change.

\subsection{Product Development}

The implementation of the endless rolling technology not only provides advantages in overall energy consumption, but also has numerous benefits in daily operation, such as

- unique geometrical strip quality and flatness,

- unique product homogeneity along the strip length (no head / tail ends),

- lowest work roll wear and reduced consumption of consumables overall,

- higher availability due to lower cobble rates / caster break outs and

- unique process stability.

The extraordinarily high process stability is a consequence of fewer production interferences and set up changes through all the process steps from the caster down to the laminar cooling section before coiling of the finished hot strip product. The endless production mode serves to ensure higher process controllability and increased homogeneity of final product properties, and maintains stable production windows for all

* Technical contribution to the 51st Rolling Seminar - Processes, Rolled and Coated Products, October $28^{\text {th }}$ to $31^{\text {st }}$, 2014, Foz do Iguaçu, PR, Brazil. 


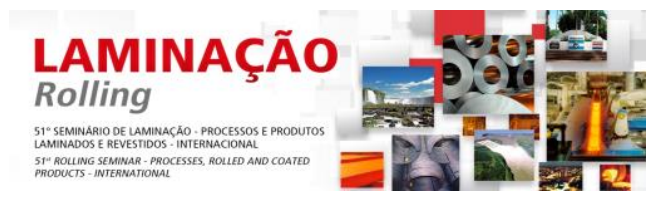

products. In particular, this is reflected in constant product speeds and temperature profiles through all the process steps from casting, and roughing to inductive reheating, finishing rolling and strip cooling. Before coiling, the endless strip is cut into coil portions by a straight cut at the high speed shear located directly in front of the downcoiler area. An important indication for intrinsic process stability is the start-up curve of a newly installed mill, as it gives an impression of the severity and total number of interruptions.

Fig. 6a provides a comparison of the ramp-up curve for different Thin Slab Casting and Rolling (TSCR) processes and the real endless ESP process, indicating that the start-up of the first ESP line already kept up with the most recent ramp up of a TSCR mill installed after decades of development.
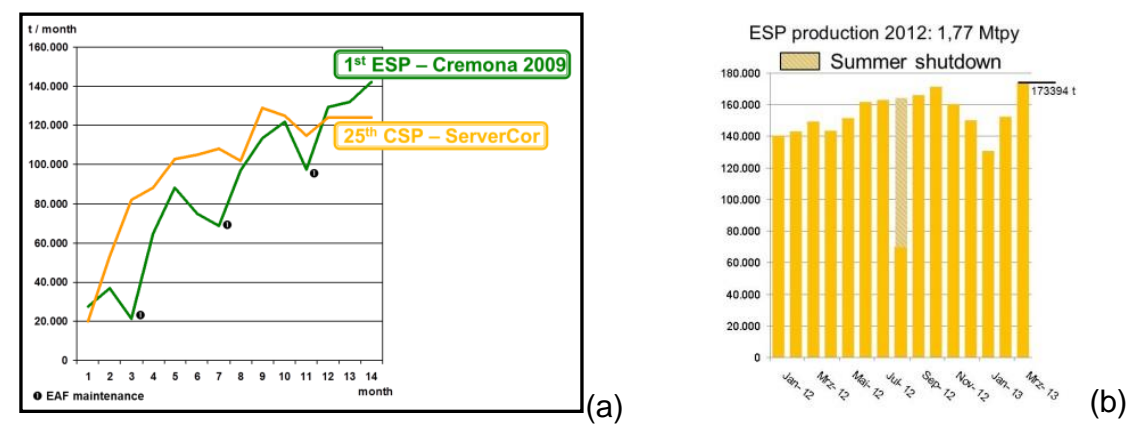

Figure 7: Monthly production per casting strand a) for the ramp-up period and b) for Arvedi ESP in 2012-2013 (production limited by meltshop capacity) [3,4].

The actual production of Arvedi ESP line is depicted in Figure 7b. The high stability of the production process along the ESP line - production parameters can be kept constant by only minor setup adjustments for approximately eight hours or 3000 tons of produced strip. This permits the possibility of narrowing the processing window, which in turn results in major cost savings compared to TSCR or conventional hot strip mills. The reason for this is that the extraordinary stability lays the basis for aggressive optimisation of alloying concepts and enables the selection of processing parameters very close to plant limits. This advantage becomes especially striking if exploited for advanced high strength steel grades, as demands in terms of process stability, alloying costs and loads are at a maximum for these.

The implementation of new grades is also facilitated by the endless concept, as process variations are kept to a minimum by construction. As a result, well-defined conditions along the whole strip ease the identification of causal relationships between processing parameters and final product properties.

The facilitated development of steel products backing on this stable process is also reflected by the fast diversification of the product range covered by the Arvedi ESP Masterplant, located in Cremona. At the end of 4 years of production it reached a variety compared to TSCR process-based mills after decades of development on several different line implementations. After it started up, several products of different demanding steel groups were produced within industrial sized trial production or even already implemented for every day production, providing Arvedi's customers with the benefits of the advanced product characteristics inherent to strip produced in fully endless mode.

* Technical contribution to the 51st Rolling Seminar - Processes, Rolled and Coated Products, October $28^{\text {th }}$ to $31^{\text {st }}$, 2014, Foz do Iguaçu, PR, Brazil. 

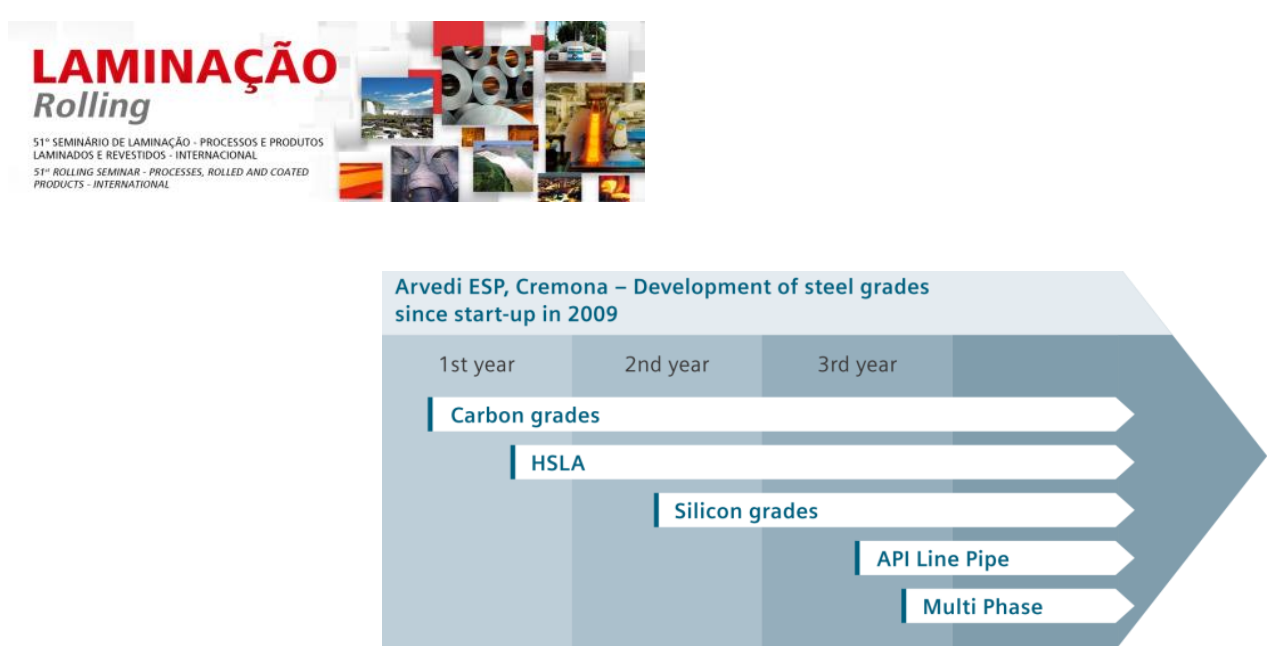

Figure 8: Development of steel grades on Arvedi ESP, Cremona since startup in 2009

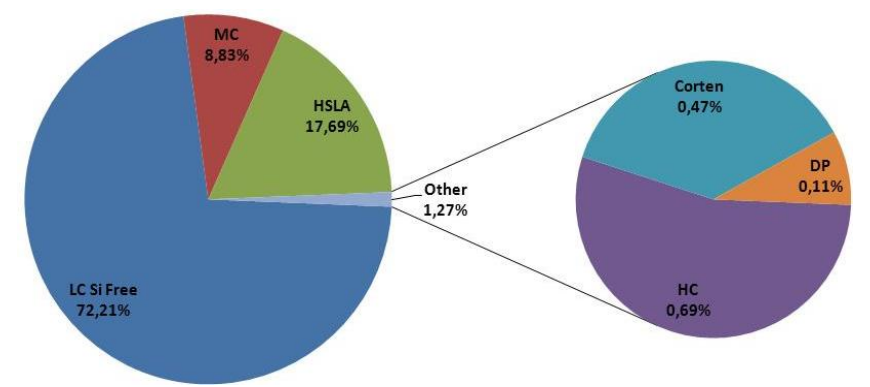

Figure 9: Arvedi ESP product mix 2012

Another advantage for product diversity is the selected line basic parameters of the ESP process, as the strand thickness lies between 70 and $120 \mathrm{~mm}$ in contrast to $45-65 \mathrm{~mm}$ at classical TSCR plants. Moreover, the two-step rolling concept including the inductive heater not only leads to a high quality of the final product geometry but also facilitates control of the target microstructure, which is critical for achieving suitable mechanical properties of the finished strip. This solution is the key to the wide product range that can be produced at the Arvedi ESP line, ranging from ultra-thin hot rolled strip to advanced high strength steels [5].

\subsection{API Certification}

Producing high quality Pipe grades is very demanding and usually challenging for mill operators. Exact Temperature guidance to meet the demands for thermomechanical rolling as well as accordingly adjusted alloying elements are the key figures. Basically, the most important characteristics of API and HSLA steel are strength, toughness, weldability and corrosion resistance.

In the conventional process, the cast slabs are stored in a slab yard, they cool down and then they are reheated for rolling Figure 11a. At this point, the microstructure consists of large grains. However, during rolling not only is the desired thickness attained but also the required fine microstructure. Conventional rolling is usually completed in two steps consisting of roughing and finishing. In the first step, the coarse initial microstructure is eradicated by massive deformation and new, small, grains are formed. The so called recrystallization takes place. However, recrystallization only occurs above a certain temperature, the non-recrystallization temperature. Below this temperature, the microalloying elements in solution are transformed into precipitates which hinder further recrystallization. The second rolling step is performed below the non-recrystallization

* Technical contribution to the 515t Rolling Seminar - Processes, Rolled and Coated Products, October $28^{\text {th }}$ to $31^{\text {st }}$, 2014, Foz do Iguaçu, PR, Brazil. 


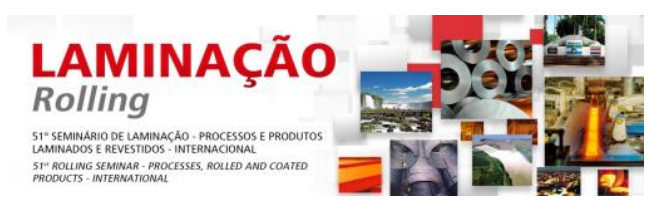

temperature, in order to achieve a "pancake" microstructure, as a basis for a finegrained final microstructure after cooling.

Thermomechanical rolling

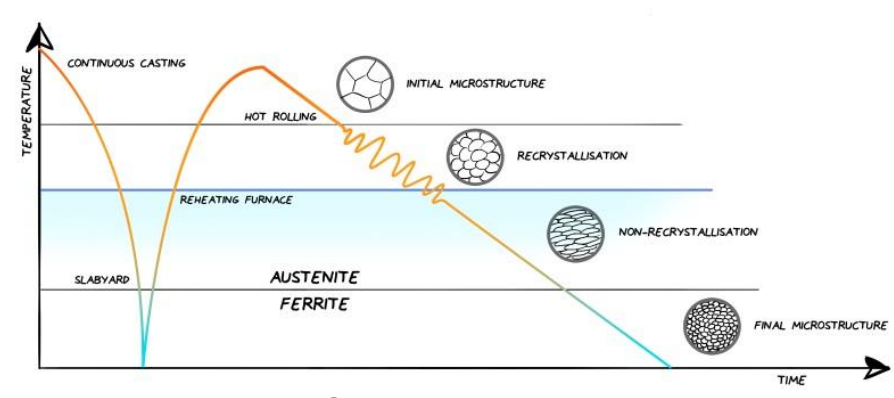

Figure 10: Grain size and temperature at Rolling step 1, Rolling step 2 and Cooling
Cooling

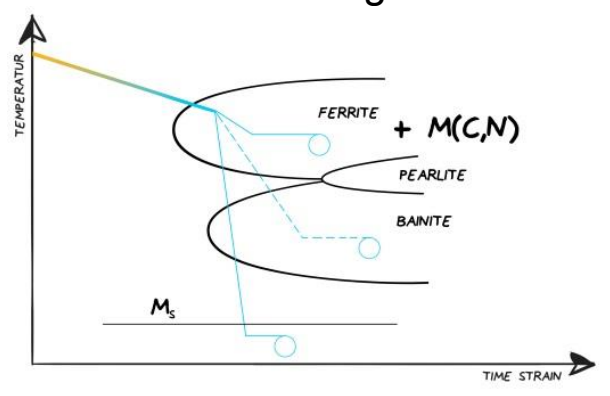

In the cooling zone, the structure of the steel is converted from a high-temperature, crystalline form known as austenite, into a low-temperature form containing ferrite and certain portions of bainite, pearlite or martensite. During this transformation, the pancaked austenite grains provide the best possible basis for the creation of a very fine ferrite microstructure. This is the origin of the high strength steel. In addition, fine grain also means first-rate toughness, which is another key feature of API grades. The defining factors for the properties of high strength steels are ferrite grain size, precipitates and the portion of other phases like pearlite, bainite and martensite.

a) Conventional hot-rolling

b) Combined casting and rolling plant with tunnel furnace working in batch mode

c) Arvedi ESP, Combined casting and rolling plant without tunnel furnace working in endless mode

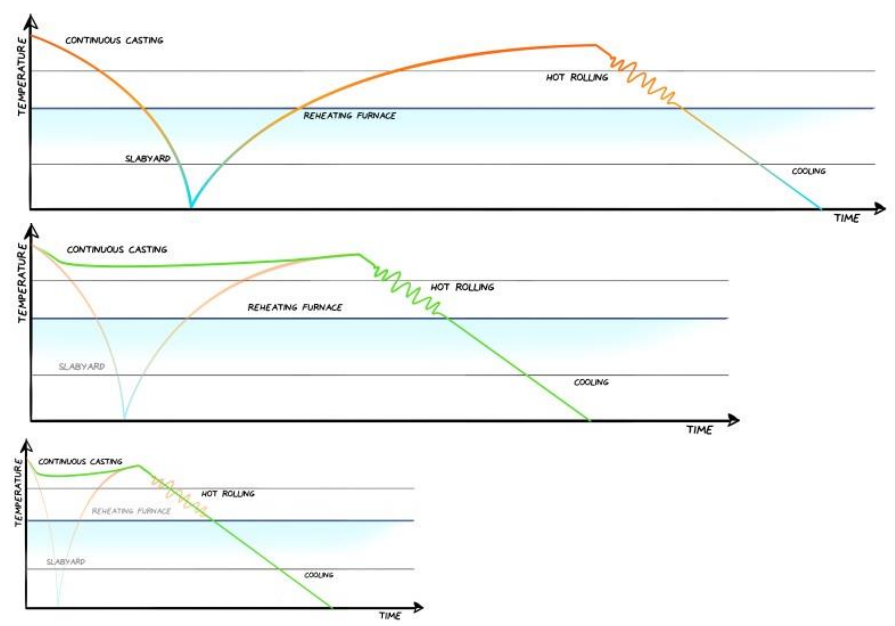

Figure 11: Process routes for hot-strip production

Precipitates are needed to control microstructure evolution during rolling and for the precipitation hardening of the finished product. This requires a sufficient amount of alloying elements in solution such as $\mathrm{Nb}$ prior to hot rolling. Each time the temperature drops, e.g. when the slabs cool, alloys in solution are gobbled up. In addition, should the temperature fluctuate during slab by slab rolling, it is essential that a finishing mill entry temperature below the non-recrystallization level is nonetheless guaranteed. This is achieved by over-alloying, which functions perfectly, but unfortunately is a rather

* Technical contribution to the 51st Rolling Seminar - Processes, Rolled and Coated Products, October $28^{\text {th }}$ to $31^{\text {st }}$, 2014, Foz do Iguaçu, PR, Brazil. 


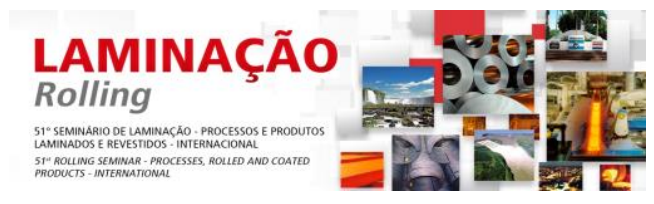

expensive way to reach the target. Extensive alloying can only be avoided by means of direct cast rolling and constant temperatures.

Over the years, a number of combined casting and rolling plants have been built, but the traditional principle remained the same s. Figure 11b. For while it's true that the slabs do not cool down to room temperature, they are still rolled slab by slab in a so-called batch process during which the temperature is subject to certain fluctuations that can only be compensated for by over-alloying. This constitutes a slight improvement, but as there is only one rolling step, the total control freedom offered by thermo-mechanical rolling is lost.

On ESP the combination of the short inductive heater with endless operation offers now again the advantage of two separate rolling steps and the possibility for exact temperature control prior to finish rolling s.Figure 11c. Accordingly, precise microstructure engineering is facilitated, which results in a dramatic reduction in the consumption of expensive alloying elements.

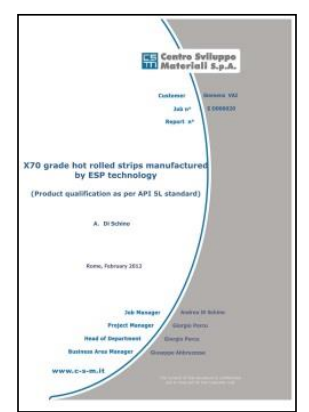

Figure 12: Certificate "X70 grade hot rolled strips manufactured by ESP technology"

\subsection{PAS 2050 - Green Certification}

When discussions come to energy consumption or the emissions of greenhouse gases (GHG) it gets difficult to compare the given figures if not being a specialist in this field. Questions come up, like: What is included? What are the conditions? For which product are the numbers valid? Comparing and analyzing given figures, it is often the problem that you do not know whether you really compare apples with apples or just apples with pears. For this reason, specialists in this field have been consulted who applied the standard (PAS) 2050, issued by the British Standards Institution (BSI). It is a specification for quantifying the life cycle GHG emissions of goods and services. To comply with the requirements of BSI PAS 2050:2011, ISO 14040, and ISO 14044 Siemens VAI and Arvedi had to collect a lot of detailed data and handed over a detailed documentation to TÜV SÜD, PE International. Additionally a critical review was made by $P E$ International AG in Echterdingen, Germany which is a renowned specialist, in the field of life cycle analyses (LCA).

The GHG emissions are evaluated in a so called cradle-to-gate study and therefore the result is the product carbon footprint (PCF) of a defined product - the functional unit including also the emissions from the used raw materials. As a well comparable product $1 \mathrm{t}$ hot rolled low alloyed low carbon S235JR steel with a thickness of $2 \mathrm{~mm}$ and a width of $1500 \mathrm{~mm}$ was selected and all relevant energy and consumption data had been collected during the year 2011. The energy consumption of the production process

* Technical contribution to the 51st Rolling Seminar - Processes, Rolled and Coated Products, October $28^{\text {th }}$ to $31^{\text {st }}$, 2014, Foz do Iguaçu, PR, Brazil. 


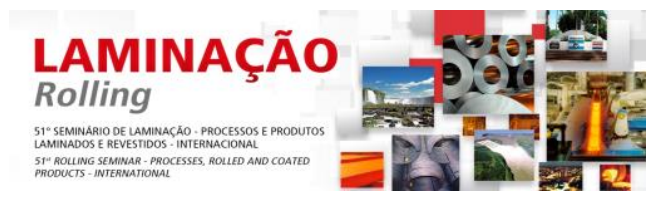

depends on the alloys, the thickness and width of the finished strip, the final steel quality, the production technology (like Arvedi ESP), the production rate, the portion of recycling material and many other parameters. The production rate, when this product was produced, was $330 \mathrm{t} / \mathrm{h}$ which is a quite high value for a single caster but usual for Arvedi ESP.

Based on a detailed documentation of the measurements the energy and other consumption data resulted in the PCF calculation. While the calculation of the energy consumption is comparatively easy and clear the calculation of the PCF is more demanding and requires a life cycle assessment software for the calculation. Main input data were energy consumption and mass flow data, not only from the ESP plant, but also the consumptions and the amount and type of scrap of the upstream located Electric Arc Furnace supplying the liquid steel. As a cradle-to-gate analysis was conducted, all relevant raw materials and preceding processes starting at the mining of the materials are considered using stored and already approved data from the Ecoinvent database. Finally a sensitivity analysis concluded the check of the most important influences to the result, like the selected power grid mix or the recycling rate of the steel scrap. The power grid mix defines the GHG burden of the supplied electrical energy.

The attestation and certification process was completed with an audit conducted at the Arvedi steel in Cremona, Italy by TÜV SÜD Industrie Service $\mathrm{GmbH}$ inspecting the whole process route including the interfaces between the different parts of the production process as well as mass and energy fluxes including losses that had to be accounted for in the calculation Further subjects of the audit were checks of measurement devices and the data acquisition system. The attestation which is an integrated part of the certificate shows that the energy consumption of the Arvedi ESP is $131.6 \mathrm{kWh}$ per functional unit. The certificate itself shows that the PCF is calculated correctly and the PCF per functional unit itself.

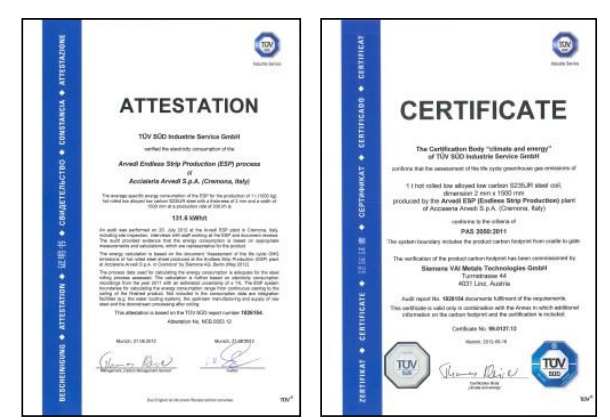

Figure 13: Attestation about energy consumption of the Arvedi ESP process and Certificate PAS 2050:2011 (2012)

\section{SUMMARY}

When the ESP concept was presented in the early years of the young century the steel world was full of doubt if such a concept could ever work. After successful operation over years the economic success of Arvedi steel verifies Arvedi ESP as a proven technology in the hard competing market of high quality hot rolled steel. The benefits cannot not only be found in the thin gauge market which is indeed just growing and extremely attractive. Also on thicker gauges the advantages are evident as uniformity

* Technical contribution to the 51st Rolling Seminar - Processes, Rolled and Coated Products, October $28^{\text {th }}$ to $31^{\text {st }}$, 2014, Foz do Iguaçu, PR, Brazil. 


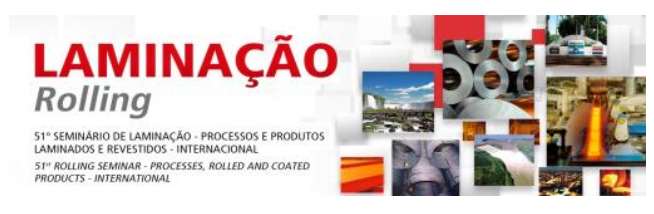

and high strip quality are a demanded factor in all market segments. The cost benefit on lower alloying requirements, breakout rate, and energy consumption, as well as the high yield is evident whatever final products are produced. With the new installations in China the investor will have a market advantage over years.

\section{REFERENCES}

1 Bragin S, Rimnac A, Linzer B, Bianchi A, Mantova A, Rizzi A, Bernhard C, Arvedi ESP process - An ultimate technology connecting casting and rolling in endless mode, European Rolling Conference 2013

2 Jungbauer G, Wersching A, Bumberger GW. Arvedi ESP Plant Integration - Business Cases and specific cost", ESP Summit 2010

3 http://www.worldsteel.org/statistics/statistics-archive/2012-steel-production.html

4 Attestation No. NCB.0053.12, TÜV SÜD Industrie Service GmbH verified the electricity consumption of the Arvedi ESP process for the production of $1 \mathrm{t}$ hot rolled low alloyed low carbon S235JR steel. (2012)

5 Certificate No. 99.0127.12, The Certification Body "climate and energy" of TÜV SÜD Industrie Service $\mathrm{GmbH}$ confirms the assessment of the life cycle greenhouse gas emissions of 1t hot rolled low alloyed low carbon S235JR steel coil, dimension $2 \mathrm{~mm} \times 1500$ $\mathrm{mm}$ produced by the Arvedi ESP (Endless Strip Production) plant of Acciaieria Arvedi S.p.A. (Cremona, Italy) conforms to the criteria of PAS 2050:2011 (2012)

6 Centro Sciluppo Materiali S.p.A. - Certificate S D006020, "X70 grade hot rolled strips manufactured by ESP technology (Product qualification as per API $5 \mathrm{~L}$ standard).

* Technical contribution to the 51st Rolling Seminar - Processes, Rolled and Coated Products, October $28^{\text {th }}$ to $31^{\text {st }}$, 2014, Foz do Iguaçu, PR, Brazil. 